\title{
Mapping Glitches of Juniper Forests in Lebanon under Natural Conditions and Anthropogenic Activities
}

\author{
Ihab Jomaa ${ }^{{ }^{*}}$, Carla Khater ${ }^{2}$ \\ ${ }^{1}$ Department of Irrigation and Agrometeorology (LARI), Tal Amara, Lebanon \\ ${ }^{2}$ Remote Sensing Center (CNRS), Mansourieh, Lebanon \\ Email: ${ }^{*}$ ijomaa@lari.gov.lb
}

How to cite this paper: Jomaa, I., \& Khater, C. (2019). Mapping Glitches of Juniper Forests in Lebanon under Natural Conditions and Anthropogenic Activities. Open Journal of Forestry, 9, 168-181. https://doi.org/10.4236/ojf.2019.92008

Received: February 23, 2019

Accepted: April 13, 2019

Published: April 16, 2019

Copyright $\odot 2019$ by author(s) and Scientific Research Publishing Inc. This work is licensed under the Creative Commons Attribution International License (CC BY 4.0).

http://creativecommons.org/licenses/by/4.0/

\begin{abstract}
In 1965, the first forest map of Lebanon was produced. It is the oldest spatial distribution representation of junipers. Landcover maps of 2002 and 2010 are the most detailed spatial distribution that spatially shows forests. Juniper forests are found in Lebanon as mainly as clear to low density coverage. High-density juniper forests are rarely found and only on Mount-Lebanon. Juniper forests are also mixed with oaks on the Eastern flank of Mount-Lebanon. Mapping juniper forests have demonstrated high degree of complexity, especially because of their low density and being mixed. The spatial representation of juniper forests was compared between the 1965 forest map and the landcover maps of 2002 and 2010. GIS environment was used to extract juniper forests from all maps. The degree of matching between juniper forests was investigated regarding the total area and spatial overlapping. Juniper forests were examined to their spatial locations, comparing the three maps. Spatial changes and anthropogenic effect were obtained, using Google Earth facilities. Google earth had satellite images acquired since 2014. Landcover maps of 2002 and 2010 have spatially matched forest map of 1965 by about $90 \%$ and $50 \%$ respectively. Spatial coverage of juniper forests were about 12,000, 26,000 and 28,000 ha on the 1965 forest map, landcover maps of 2003 and 2010 respectively. Anti-Lebanon juniper forests were not well represented on both landcover maps. Anthropogenic activities were mainly agriculture that affected juniper forests. Cultivations have replaced about $2 \%$ of the spatial coverage of 1965 Juniper forests. Quarries and urban existed inside juniper forests but in very limited areas. Juniper forests delineation did not completely match neither between the available maps, nor to the ground. Some juniper forests were not spatially represented on all maps or existing maps represented only portion of juniper forests. Juniper forest mapping requires more consideration
\end{abstract}


and field investigation. High spatial resolution satellite images are among the solutions but delimiting juniper would require extensive fieldwork and specific remote sensing treatments. Being centuries old forests and characterized by High Mountain elevations, these important conifer forests are needed to be mapped with higher accuracy for better statistics and conservation.

\section{Keywords}

Conifer Forests, High Mountain Forests, Landcover Maps, Low-Density

Forests, Conservation Juniperus excelsa

\section{Introduction}

Spatial representation of Juniper forests on mountains of Lebanon is challenging. Maps showing the spatial distribution of junipers have started since the 1960s. Aerial mission of 1962 was the starting point for various maps over the country. Forest map of El Husseini and Baltaxe (1965) was the most detailed one over all the country prepared on a scale of $1 / 50,000$. On this map, the spatial coverage within forest patches of junipers describes the percent cover and density of trees. The tree density was defined as broken small patches of $10 \%-30 \%$ and more than $30 \%$. Therefore, it is evident that in 1965, juniper tree-stands of junipers were highly dispersed except in few localities. Other maps of landcover and/or forest of Lebanon have mentioned the presence of juniper stands but with fewer details. The MOS (Mode d'Occupation du Sol) is the landcover map of Lebanon of 1998 that was published in 2002; junipers forests were described as open wooded lands or open junipers forests (MoA, 2002). Open woodlands were further described as coverage of less than $60 \%$ but no less than 10 to $15 \%$. MOS map has delineated juniper forests on $1 / 20,000$ spatial scale which provided the ability to enhance delimitation accuracy of such challenging forests. Another landcover map was published in 2010. Landcover map of 2010 was prepared primarily based on satellite images of 2005. Once the juniper spatial distribution is compared between all existing maps, variability appears clearly. As an example, juniper forest cannot exist in 1965, disappear in 2002, and then return in 2010. Variation between juniper forests delimitation has to be deliberated once comparing various maps (Jomaa et al., 2007, 2008, 2009).

Juniper stands start to appear from lower altitudes mixed with oaks until it reaches higher elevations where oaks disappear. Once pure, junipers exist mostly in open forest stands of low spatial density. Dense juniper forest rarely occurs in Lebanon. Nevertheless, being in some places mixed with other forest types, junipers are difficult to be mapped. Wide-open forests will require high spatial resolution satellite images to locate even trees. Low spatial resolution satellite images are not capable in identifying singletree stands. Hyperspectral satellite images could be used for mixed forest localities (Awad et al., 2014). Landcover maps will continue to be established by the National Council for Scientific Re- 
search (CNRS) or other organizations, using remote sensing techniques. The accuracy of landcover maps will be variant in accordance with the type of the landcover. Juniper forests are not well delimited because of the already mentioned reasons.

New anthropogenic activities on elevated mountains are sneaking into and between juniper forests. Agriculture is shifting toward higher mountains taking over the existing forests. Roads are excavated cutting higher altitude forests into fragmented patches (Jomaa \& Bou Kheir, 2003; El-Hajj et al., 2014; Darwish et al., 2018). Water harvesting reservoirs are another cause of cutting through the forests. Cultivated areas are mainly found on narrow mountain valleys but terraces are also appearing between juniper forests. Therefore, mapping juniper forests is getting more complications because of the anthropogenic effect.

Forest maps of Lebanon are for the years 1965, 1966 and 2005 of spatial scale 1/50,000, 1/200,000 and 1/20,000 respectively (El Husseini \& Baltaxe, 1965; MoA, 2002; NFA, 2005). The last one was printed on $1 / 200,000$ spatial scale, but the spatial distribution of the forest patches coincide largely with the landcover map of 2002. Therefore, the landcover map of 2002 could spatially replace the forest map of 2005. Although, juniper forests spatial representation coincide between maps in certain locations, but they largely differ in other places. Location of juniper forests matches in to a certain degree in one area but they are completely off in others. For example, patches that appear in date one map are not found in date two map in several locations and the opposite is true.

This work aims to spatially characterize juniper forests and determine the concurrent anthropogenic effect. It also studies the anthropogenic activities on mapping of such forests. The study clarifies the spatial difference between various data sources and previous maps in representing juniper forests. The approach demonstrates the complexity of spatially representing juniper forests and it shows how previous maps are somehow ambiguous in locating such forests.

\section{Materials and Methods}

Lebanon is country of $10,452 \mathrm{~km}^{2}$; with $72 \%$ of the territory are mountains. Mount Lebanon reaches to an elevation of $3088 \mathrm{~m}$ at El Qornat Al Sawda to the north. Agriculture expands over the mountains, starting from foot slopes to more than $2000 \mathrm{~m}$ altitude. Extending from southeast to northwest, the two mountain chains are characterized by rugged geomorphology. Mount-Lebanon could be divided between coastal flank and inner slope facing inlands. Anti-Lebanon facing the Bekaa valley at $1000 \mathrm{~m}$ elevation and rise to an altitude of about $2800 \mathrm{~m}$.

Forests of Lebanon are mainly found on the mountains. Junipers are the high elevation mountains. Juniper stands start at $1500 \mathrm{~m}$ of elevation as individual trees between oaks. Junipers appear in denser stands between 1800 and $2500 \mathrm{~m}$ of altitudes. Junipers forest patches are located on the two Lebanese mountain chains "Mount Lebanon and Anti-Lebanon". The mountains are of rugged to- 
pography where narrow valleys might have juniper stands.

\subsection{Forest and Landcover Maps}

Forest spatial data was derived from landcover and forest maps of Lebanon. The oldest spatial forest representation was obtained from the 1965 forest map at $1 / 50,000$ scale. The second forests spatial representation was extracted from the landcover map of 2002. The last juniper forest patches were derived out of the 2010 landcover map. Juniper forest patches were extracted on a GIS environment.

\subsection{Forest Map of 1965}

The first Lebanon aerial mission of 1962 has allowed the preparation of the 1965 forest map on 1/50,000 scale (Figure 1). Juniper forest patches were represented on three different spatial characteristics:

- Juniper forests of more than $30 \%$ density cover.

- Juniper forests of $10 \%$ - $30 \%$ cover.

- Junipers forests of broken small patches of $10 \%-30 \%$ cover.

\subsection{Landcover Map 2002 and 2010}

Landcover map of 2002 was prepared based on satellite images of the year 1998 .

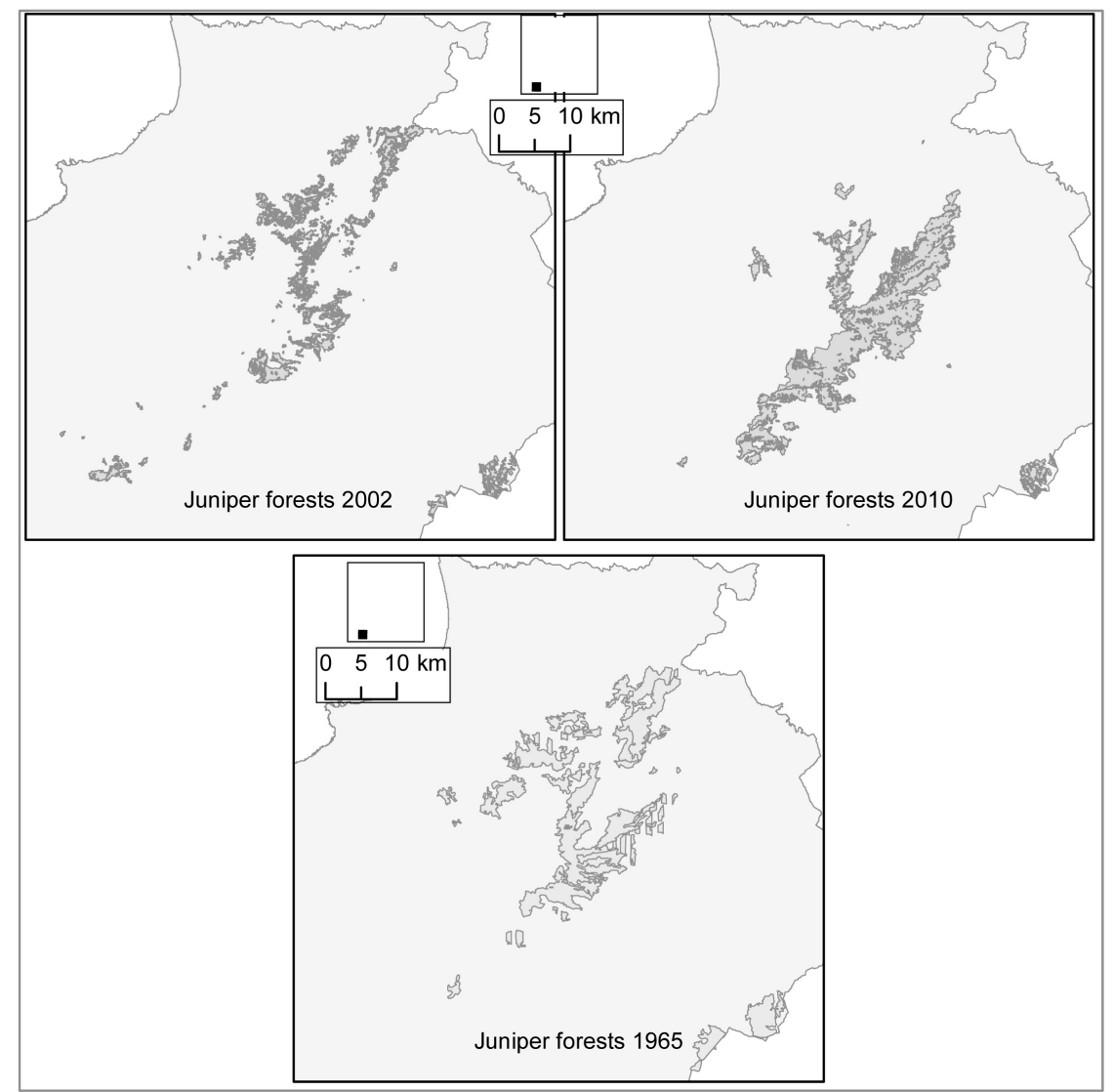

Figure 1. Juniper forests spatial distribution of 1965, 2002 and 2010. 
The landcover map was prepare on a digital format at $1 / 20,000$ spatial scale (Figure 1). Juniper forest patches were only represented by their density to one characteristic "open Juniperus spp.".

The National Forest Assessment (NFA) has used same forest patch spatial distribution of MOS 2002 (NFA, 2005). Therefore, this work has only relied on the original map distribution of forests, i.e., MOS. Landcover of 2010 was produced based on satellite images of 2005. Junipers were represented as clear forests of less than $60 \%$ coverage.

\subsection{Anthropogenic Effect on Juniper Forests}

Anthropogenic activities, like quarries, agriculture and urban, are taking place within juniper forest patches (Figure 2). These activities are replacing the spatial coverage of junipers without being mapped for subtracting them from junipers spatial coverage. Anthropogenic-effect on juniper forests was investigated through field visits and Google Earth facilities. Field visits took place in 2011 to locate juniper forests and examine anthropogenic effect. Juniper forests were investigated on 30 different sites. Juniper stands were inspected if they were cut. Forest patches that disappeared between various maps where field investigated.

The spatial representation of juniper forests on various maps were converted to Google Earth compatible, using GIS tools. The spatial patches were then installed on Google Earth where main anthropogenic effect has mapped. Agriculture activities within previously delineated juniper forests were easily demarcated. Deforestation has also been spotted inside juniper patches of existing maps. Deforestation was defined as empty spaces of no tree stands. Excavated areas where also delimited.

\subsection{Comparing Various Map Sources}

Existing maps of forests and landcover do not fully coincide between each other in delimiting juniper forests (Figure 3). Juniper trees live for centuries and cannot be present suddenly as aged stands within short periods. Existing new locations of juniper stands are spotted and delimited. Missing sites were compared
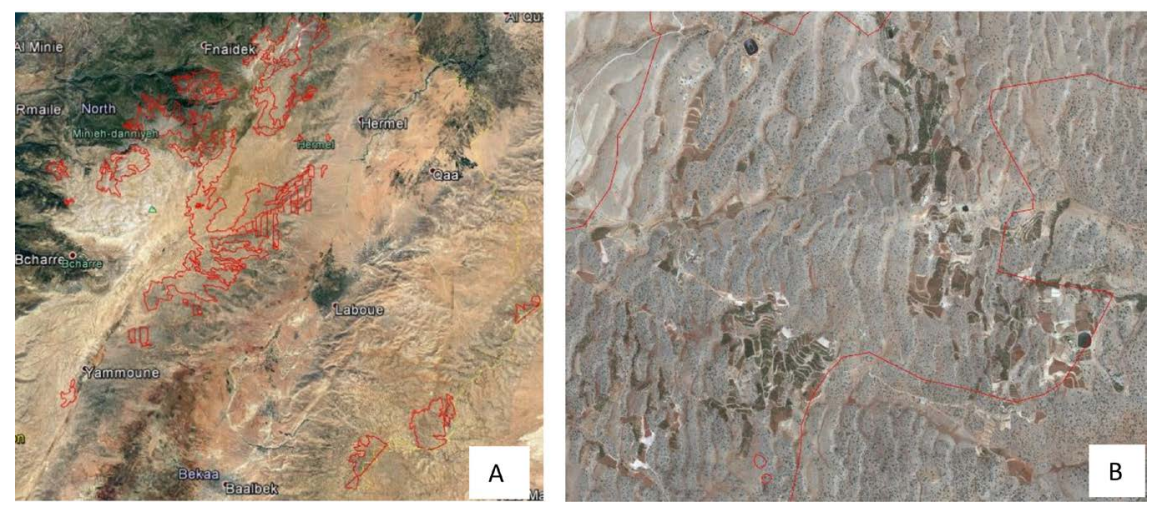

Figure 2. Juniper spatial patches of 1965 (A); Agriculture (dark green) inside junipers patches in 2014 (B). 


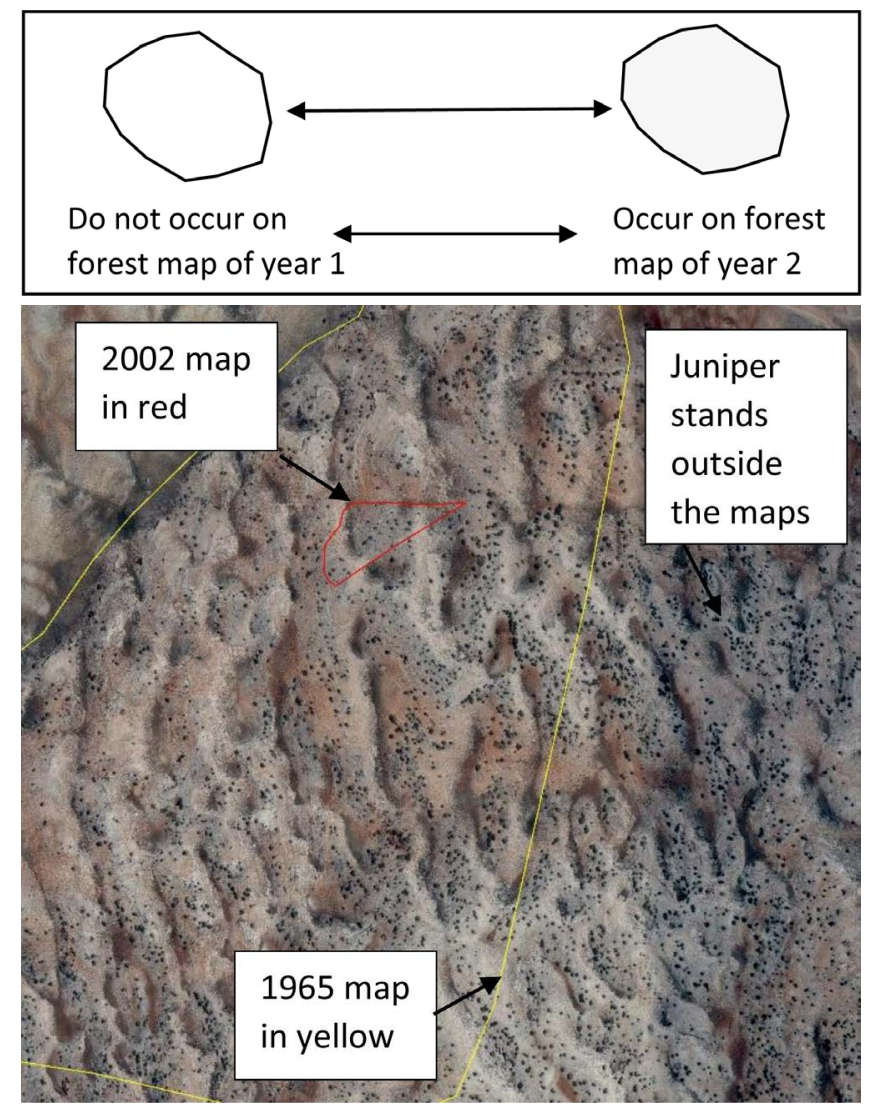

Figure 3. Comparing map forest patches.

between existing maps. These missing forests sites were then compared on Google Earth facilities and through field investigations. On the other hand, some other forest patches might be miss-designated as junipers on newer maps.

Juniper forests were compared between each other and ground truth. The miss-match sites between maps were delineated and described. Google Earth facilities were also used to match results.

\section{Results and Discussions}

\subsection{Juniper Forest Coverage}

Juniper coverage has been registered differently on the various maps, i.e., landcover maps of 2002, 2010 and forest map of 1965 (Figure 4). The total covering area of Junipers is about $12,000,26,000$ and 29,000 ha on the landcover maps 2002, 2010 and forest map of 1965 respectively. Neighboring juniper forests, the landcover map of 2002 has about 7500 ha of mixed forests that could hold juniper trees.

The total forest cover area does not reflect the accuracy of the spatial distribution. The landcover map of 2002 matches the 1965 forest map by about $90 \%$ of the area distribution of junipers. While the landcover map of 2010 matches to about 50\% from the forest cover spatial distribution when compared to the 1965 forest map. Although these results reflect the degree of variability between the 


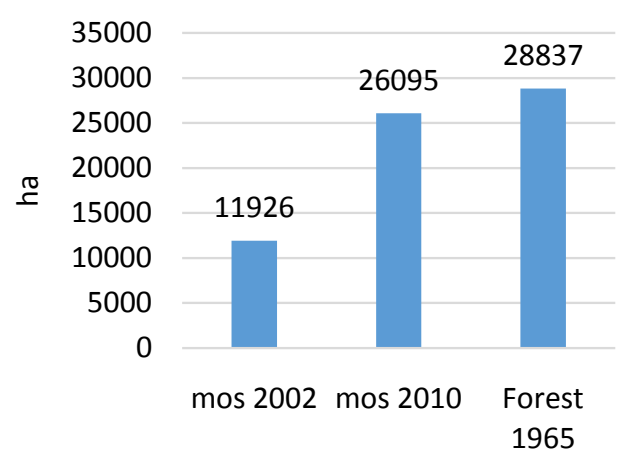

Figure 4. Total forest coverage of on the landcover maps 2002, 2010 and forest map of 1965.

maps show juniper spatial distribution, the maps are of different spatial scale. However, the difference in the spatial scale will not cause high degree of variability in the spatial representation of forests.

\subsection{Juniper Forests Miss Delineations}

The three maps, i.e., forest map of 1965, landcover map of 2002 and landcover map of 2010 show juniper forests in similar areas in one location and do not match at other places (Figure 5). Although these maps have time lapse between 35 and 8 years, field investigation demonstrated the requirement of re-considering the delimitation of such juniper forests.

Juniper forest was subjected to cutting and deterioration between 1965 and 2010. Therefore, some places were not delineated on landcover maps of 2002 and 2010 (Figure 6). At the west of Hermel village, the area to the northeast of Marjhine has subjected to degradation of juniper forests. This area was registered on forest map of 1965 , as broken patch of $10 \%-30 \%$ density. There was great loss of juniper trees in this area, the broken patches are no longer exist. Few separated juniper trees are rarely found across this area. However, other places were not registered as juniper on both landcover maps. The area of Anti-Lebanon has been delineated differently between both landcover maps, although forest places of 1965 still exist. Locations of junipers forest largely matches when comparing the 1965 forest map and the landcover map of 2002. However, great variability in forest locations do exist between 1965 and 2010 landcover map.

Juniper forests of Anti-Lebanon were not all assigned on the landcover map of 2010. At the East of Aarsal village is the only location were the 2010-forest map showing juniper stands of Anti-Lebanon. Other locations on the Anti-Lebanon (red patches) are not delineated although juniper forests exists. Boardering Tfail village, at the boarder with Syria, is another example where 1020 landcover map does not delineate forests (Figure 7). Figure 7 shows red patches as locations of 1965 juniper; while Green ones as the only locations delimiting as junipers on the Anti-Lebanon mountain chain. These juniper forests were assigned as fruit trees. 


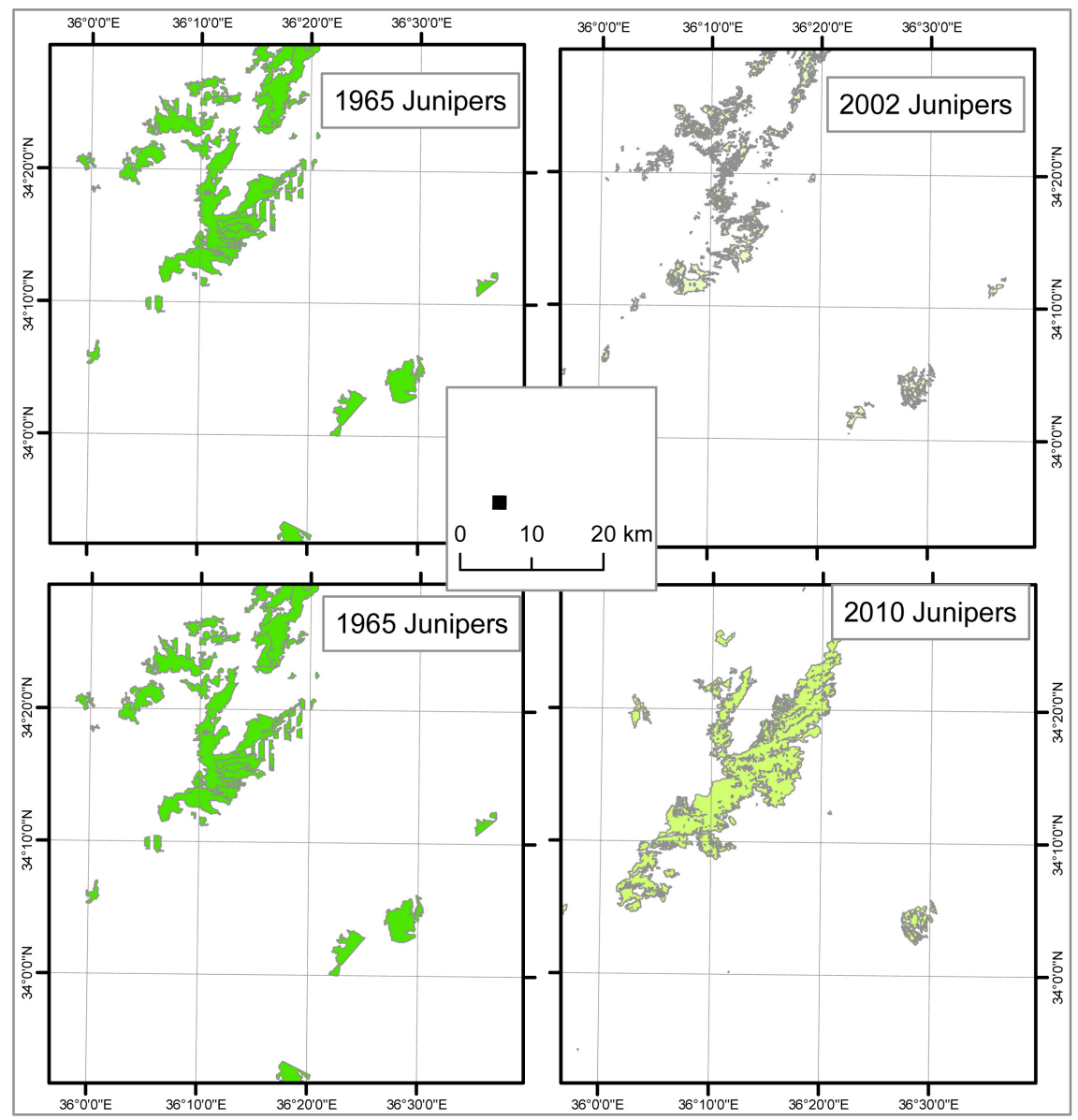

Figure 5. Comparison of juniper forests between maps of 1965, 2002 and 2010.

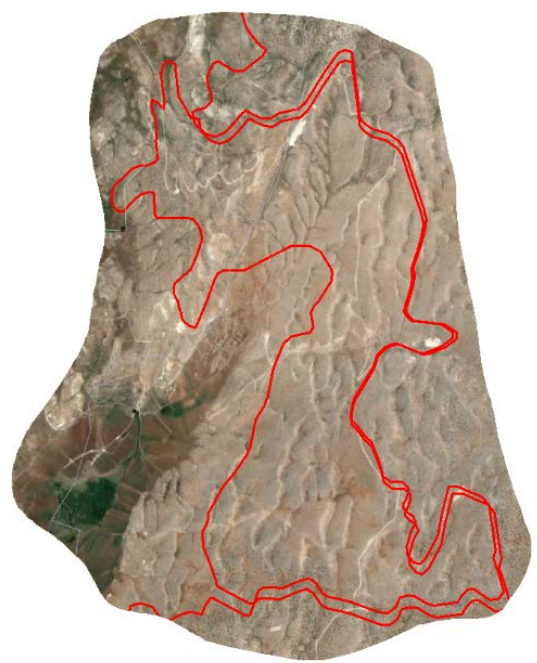

Figure 6. Northeast of Marjhine, largely degraded juniper forests.

In 2002 landcover map, juniper forests were also not all delineated on the Anti-Lebanon mountain chain. Forests stands were classified as open field crops and grasslands next to Tfail village. Figure 8 shows blue patches as junipers of the 2002 forest map while the red patches are junipers of 1965 forest map. 

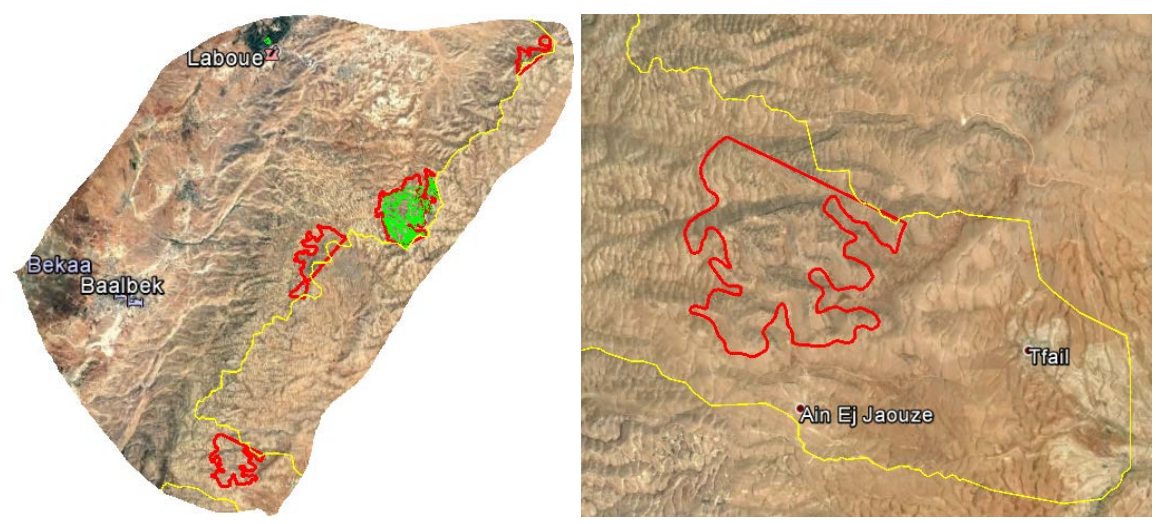

Figure 7. Juniper delineation at Anti-Lebanon mountain chain: red patches are for the 1965 forest map and green are for the landcover map of 2010.

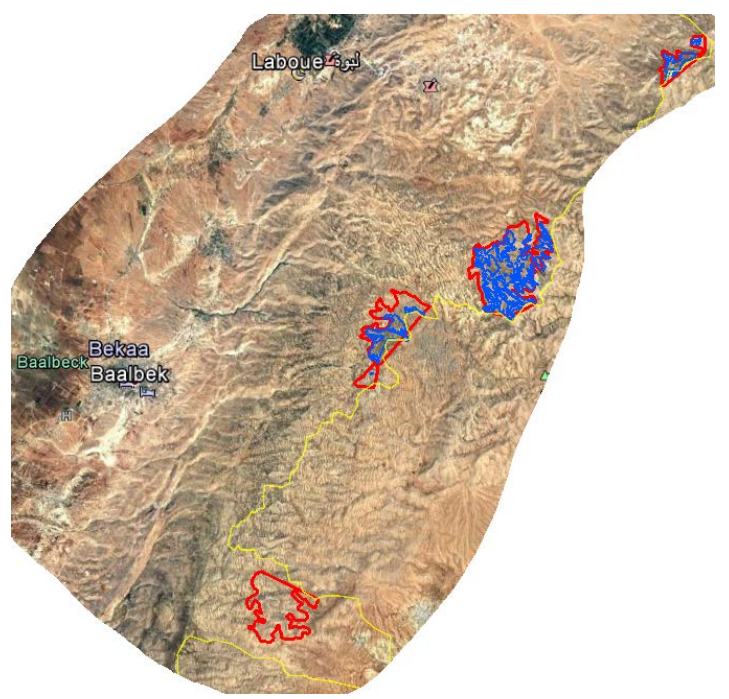

Figure 8. Juniper forests as blue patch of 2002 landcover map and as red patches of 1965 forest map.

On Mount-Lebanon, landcover map of 2002 delineated new location of juniper forests that they were not delimited on both forest map of 1965 and landcover map of 2010 (Figure 9). Adding, juniper forests were not delineated at other locations of Mount-Lebanon. Large areas that hold juniper forests at Mount-Lebanon were not assigned as junipers but they were listed under mixed clear forests. As example, neighboring Afqa village, juniper were only delineated on the landcover map of 2002. These places are not forest rehabilitation but they are location of old forest stands. Existing maps do not cover all location of junipers forests. Some maps are better than others but globally juniper forests are not well spatially represented. Even a location was spotted to have juniper trees on the 2002 landcover map, juniper trees were not all delineated. Large areas of juniper trees were fitted into other landcover objects such open grass lands and fruit trees.

At the eastern flank of Mount-Lebanon, on 2010 landcover map, facing the Bekaa Valley, oak forests were listed as clear juniper forests (Figure 10). Oak forests 


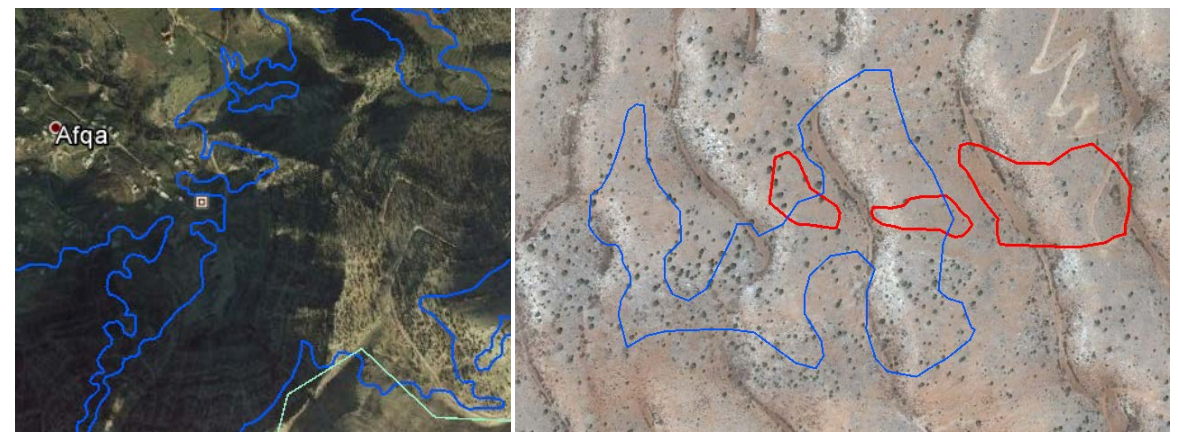

Figure 9. Landcover of 2002 delineating new location of juniper forests on Mount-Lebanon.
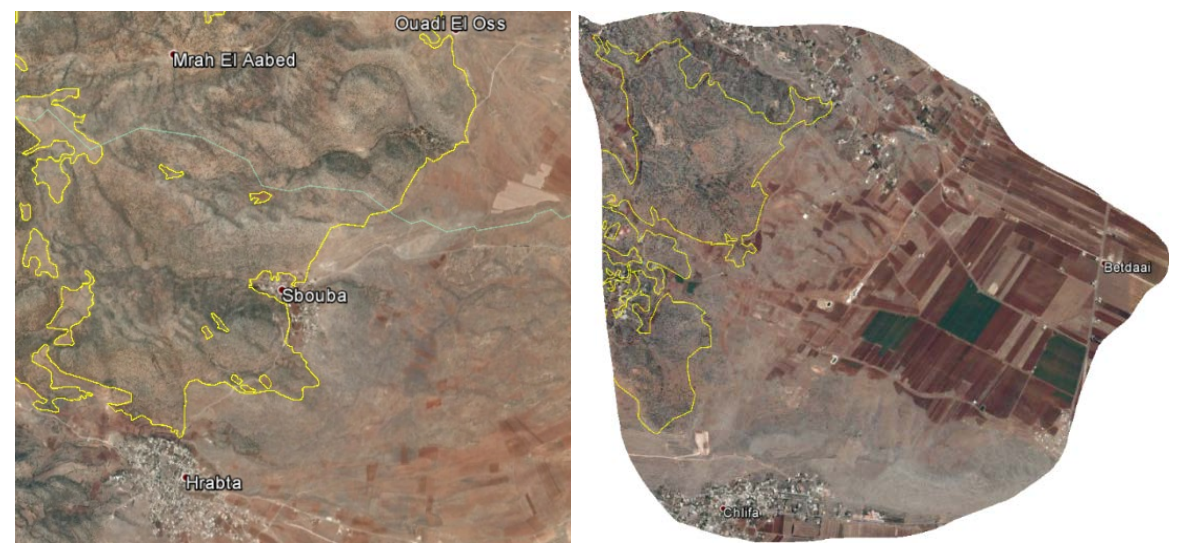

Figure 10. Oaks of Eastern flank of Mount Lebanon, delineated as juniper on the 2010 landcover map.

are found on lower altitudes, thus juniper stands should be delineated taking into consideration elevations.

Mismatching between maps did not always relate to landcover changes. Juniper patches appear in places where there are not junipers or maps might not delineate existing forests (Figure 11). A juniper parch of about 14 ha was mistakenly assigned as junipers on the 2010 landcover map. Although it is a small patch, such delineation mismatching reflects the degree of intricacy in spotting juniper trees. The mismatched juniper patch is in reality fruit trees next to Laboue village at the northern part of the Bekaa.

\subsection{Anthropogenic Activities within Juniper Forest Patches}

Agriculture took over large areas inside the 1965 juniper forest patches (Figure 12). Total agriculture area has reached about 540 ha which makes about $2 \%$ of the 1965 delineated juniper forests. Agriculture expansion over the forests was mainly correlated to the neighboring urban agglomerations. Cultivation is being accomplished on terraces or using narrow valleys and drainage tributaries. The majority of cultivations are trees of stone fruits with narrow valley of vegetable and field crops.

Forest trees are kept between cultivated terraces once lands are hard to be excavated (Figure 13). Juniper trees are also trapped inside cultivated land and 


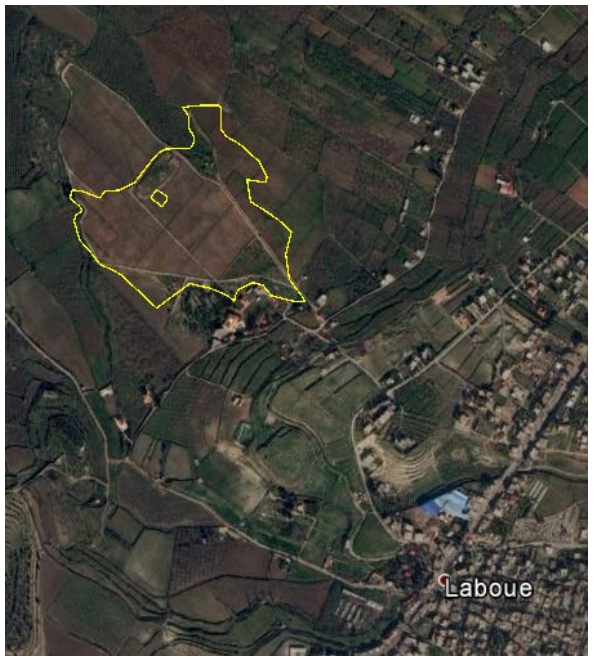

Figure 11. Mis-mapped juniper patch on the 2010 landcover map.

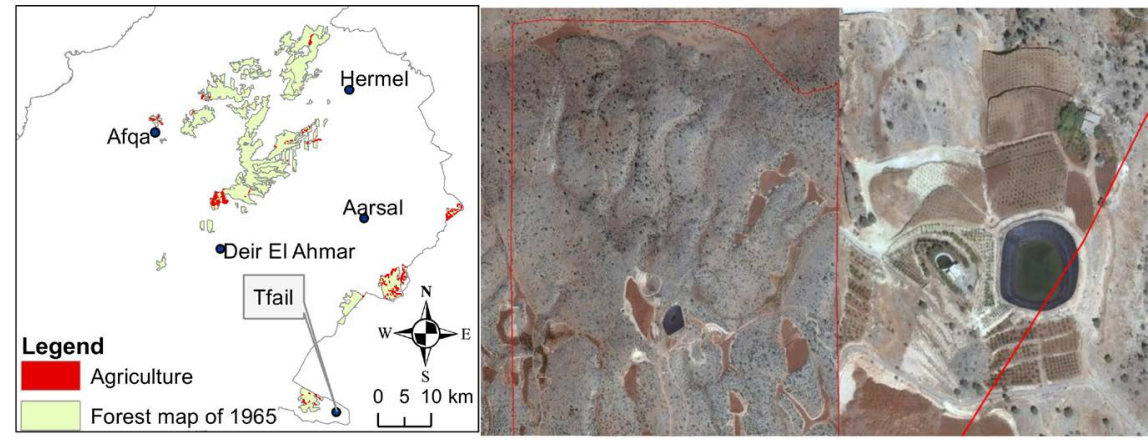

Figure 12. Agriculture inside juniper forest patches of 1965. Cultivation on terraces and narrow valley across juniper forest patches.

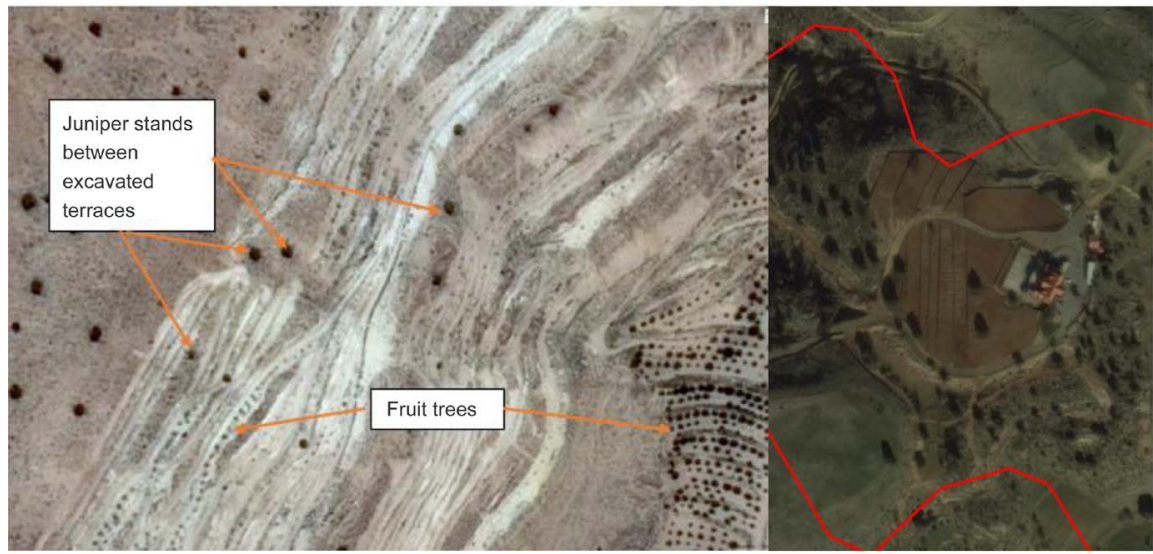

Figure 13. Juniper trees trapped between terraces, cultivated lands and home gardens.

home gardens. However, cutting is also another solution for people to expanding urban and agriculture. Farmers tend not to cut juniper trees that they have minimum effect on the agriculture practices. Some farmers do not dare in violating regulations while deciding to keep or cut down forest trees. While others destruct trees gradually, in a manner, that it appears like naturally died while 
others might put down forest trees directly.

Water harvesting reservoirs are excavated inside forest patches (Figure 14). These water reservoirs are used for irrigation purposes. Roads are cut to reach the newly established reservoirs and water pipes are dug in between forest stands toward cultivated lands. Nevertheless, water harvesting reservoirs are causing degradation and erosion of nearby forest trees. On the other hands, new roads are cutting throughout the forests and quarries was also found inside juniper forests of Anti-Lebanon. Forest was affected through the dust of adjacent quarries.

Cutting of juniper forests is occurring periodically (Figure 15). After first violated cut, junipers might regenerate and grow again to make new tree to the side. Other cuts are also happening after years of tree growth. Therefore, the

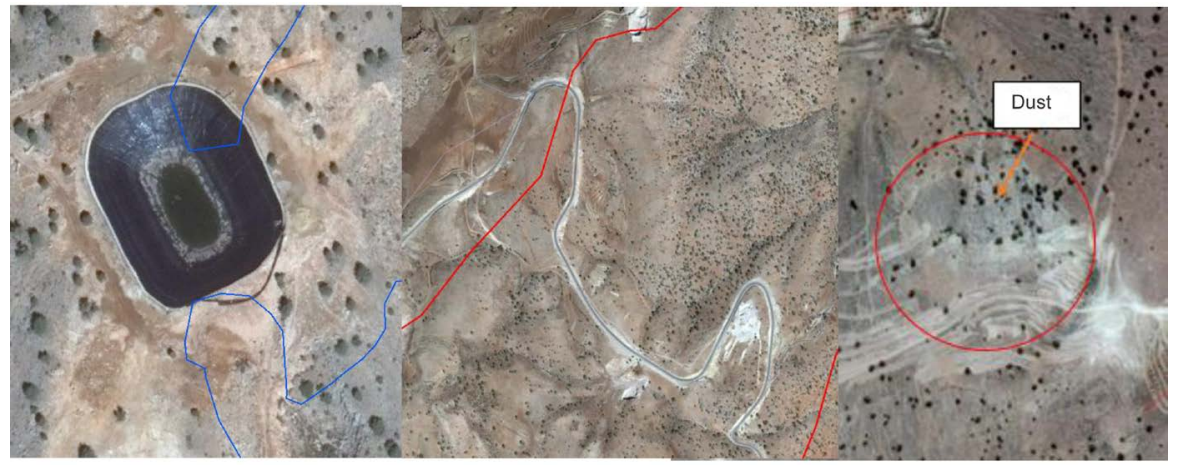

Figure 14. Soil erosion next to water harvesting reservoirs. Roads cutting inside forests. Dust after excavation inside forests.

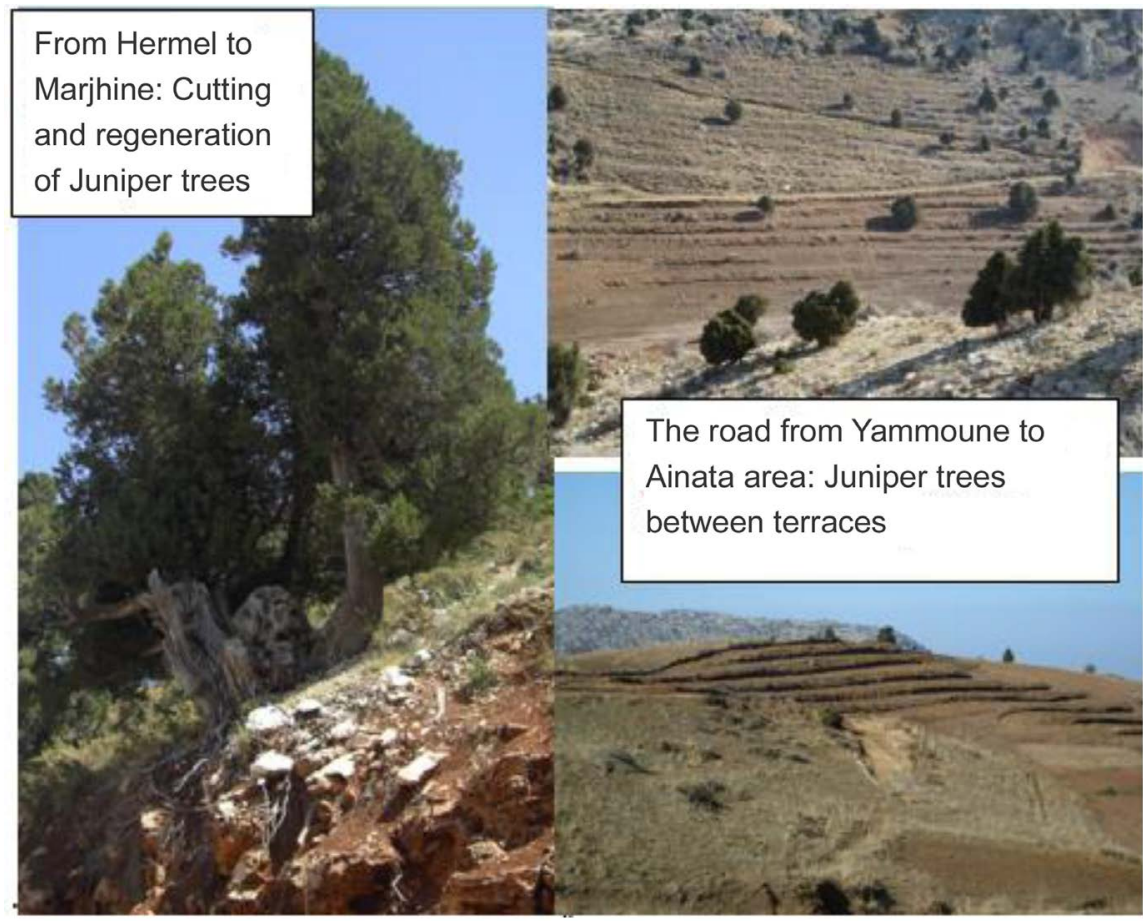

Figure 15. Cutting of juniper forests. Juniper trees between terraces. 
need to cut forest trees continue through generations because juniper trees take 100 years to grow into full tree again. It is expected that cutting will occur several times on the same tree stand.

\section{Conclusion}

This research highlighted main difficulties when it is intended to spatially representing juniper forests. In Lebanon, juniper forests are mostly of clear coverage. Satellite images of low to medium spatial resolution will not spot individual trees. On the other hand, high-resolution satellite images would require great deal of time and accuracy checking on their treatments. Fieldwork is an integral part to increase accuracy of image classifications.

Current spatial coverage of juniper forests catches the majority of forest patches, especially the 1965 forest map and the landcover map of 2002. Landcover map of 2010 has major areas that do not match the real spatial representation of junipers. Elevation checking has to be performed on mapped junipers, eliminating acute misidentifications, e.g. landcover map of 2010 has small patch designated as juniper forest in the middle of the Bekaa Valley. Mapping juniper forests should be accomplished through comparing previous existing maps and intensifying field investigations.

\section{Acknowledgements}

This work is part of the project entitled "Mapping and monitoring juniper forests in Lebanon, creating a standard methodology using remotely sensed data" funded with support from the National Council for Scientific Research (CNRS-Lebanon); Thanks go to CNRS-L for supporting such project for a sustainable management of forest resources in Lebanon.

\section{Conflicts of Interest}

The authors declare no conflicts of interest regarding the publication of this paper.

\section{References}

Awad, M., Jomaa, I., \& Arab, F. (2014). Improved Capability in Stone Pine Forest Mapping and Management in Lebanon Using Hyperspectral CHRIS-Proba Data Relative to Landsat ETM+. Photogrammetric Engineering and Remote Sensing, 80, 725-732.

Darwish, T., Abou Daher, M., Jomaa, I., Faour, G., Awad, M., \& Hamze, M. (2018). Soil Forest Ecosystem and Forest Fire Effect on Soil Organic Carbon Stock in Lebanon. Journal of Life Sciences, 12, 47-58. https://doi.org/10.17265/1934-7391/2018.01.005

El Husseini, K., \& Baltaxe, R. (1965). Forest Type Map at 1/50,000 Scale. Lebanon: Forestry Education, Training and Research Project, Green Plan, United Nations Special Fund/FAO.

El-Hajj, R., Al-Jawhary, D., Moukaddem, T., \& Khater, C. (2014). Forest Sustainability in North Lebanon: A Challenging Complexity in a Changing Environment. International Journal of Forestry Research, 2014, Article ID: 212316. 
https://doi.org/10.1155/2014/212316

Jomaa, I., Auda, Y., Abi Saleh, B., Hamze, M., \& Safi, S. (2008). Landscape Spatial Dynamics over 38 Years under Natural and Anthropogenic Pressures in Mount Lebanon. Landscape and Urban Planning, 87, 67-75. https://doi.org/10.1016/j.landurbplan.2008.04.007

Jomaa, I., Auda, Y., Hamze, M., Abi Saleh, B., \& Safi, S. (2009). Analysis of Eastern Mediterranean Oak Forests over the Period 1965-2003 Using Landscape Indices on a Patch Basis. Landscape Research, 34, 105-124. https://doi.org/10.1080/01426390802591569

Jomaa, I., \& Bou Kheir, R. (2003). Multitemporal Unsupervised Classification and NDVI to Monitor Land Cover Change in Lebanon. Options Méditerranéennes, Série B, No. 46, 43-49.

Jomaa, I., Auda, Y., \& Khater, C. (2007). Contribution to the Characterization of Forest Fragmentation on the Eastern Flank of Mount Lebanon over 33 Years. Lebanese Science Journal, 8, 59-74.

MoA (2002). Landcover Map of Lebanon-Obtained from Satellite Images of the Year 1998 (Landsat TM 5 Merged to IRS Panchromatic). Prepared by the Lebanese National Council for Scientific Research (CNRS), Remote Sensing Center, with the Collaboration of IAURIF (Institut d'Aménagement et d'Urbanisme de la Régiond'Ile de France), LEDO Program, UNDP, Ministry of Agriculture and Ministry of Environment (Lebanon).

NFA (2005). National Forest and Tree Assessment and Inventory. Technical Corporation Program, Lebanon (TCP/LEB/2903) between 2003 and 2005, Ministry of Agriculture. 